\title{
Evaluation of surface integrity after high energy machining with EDM, laser beam machining and abrasive water jet machining of alloy 718
}

\author{
Jonas Holmberg $^{1,2} \cdot$ Johan Berglund ${ }^{1} \cdot$ Anders Wretland $^{3} \cdot$ Tomas Beno $^{2}$
}

Received: 22 December 2017 / Accepted: 11 September 2018 /Published online: 5 October 2018

(C) The Author(s) 2018

\begin{abstract}
Development of future aero engine components based on new design strategies utilising topological optimisation and additive manufacturing has in the past years become a reality. This allows for designs that involve geometries of "free form" surfaces and material combinations that could be difficult to machine using conventional milling. Hence, alternative manufacturing routes using non-conventional high energy methods are interesting to explore. In this investigation, the three high energy machining methods abrasive water jet machining (AWJM), electrical discharge machining (EDM) and laser beam machining (LBM) have been compared in terms of surface integrity to the reference, a ball nosed end milled surface. The results showed great influence on the surface integrity from the different machining methods. It was concluded that AWJM resulted in the highest quality regarding surface integrity properties with compressive residual stresses in the surface region and a low surface roughness with texture from the abrasive erosion. Further, it was shown that EDM resulted in shallow tensile residual stresses in the surface and an isotropic surface texture with higher surface roughness. However, even though both methods could be considered as possible alternatives to conventional milling they require post processing. The reason is that the surfaces need to be cleaned from either abrasive medium from AWJM or recast layer from EDM. It was further concluded that LBM should not be considered as an alternative in this case due to the deep detrimental impact from the machining process.
\end{abstract}

Keywords Non-conventional machining $\cdot$ EDM $\cdot$ Laser beam machining $\cdot$ Abrasive water jet machining $\cdot$ Surface integrity Residual stress $\cdot$ EBSD $\cdot$ Topography

\section{Introduction}

\subsection{Background and objectives}

High speed milling with ceramic tools followed by different tempos using cemented carbide tools into a final geometry is the conventional manufacturing method of aero engine parts today. This production route is often problematic and time consuming due to the materials' high resistance to be machined. The reason for this is mainly the materials' high strength at elevated temperatures. Further, these materials also

Jonas Holmberg

jonas.holmberg@swerea.se; jonas.holmberg@hv.se

Swerea IVF AB-Manufacturing, Mölndal, Sweden

University West-Production technology, Trollhättan, Sweden

GKN Aerospace Sweden AB, Trollhättan, Sweden have a tendency to deformation harden which makes the situation even more complicated. The deformation hardening mechanism, especially at low feed and shallow depth of cut, is often related to high cutting forces that generate high wear of the cutting tool edges [1].

However, new and emerging technologies involving additively manufactured material, topologically optimised designs and fabrication of parts offer a more material resource efficient production compared to the traditional one where large castings are machined to final shape [2-4]. For such manufacturing, conventional milling could be problematic because it involves machining of difficult geometries as well as materials that may have different properties. However, with high energy methods, this machining could be made possible in one setup.

Consequently, the need for high energy machining methods, electrical discharge machining (EDM), laser beam machining (LBM) and abrasive water jet machining (AWJM), in particular for products that include "free forms" such as undulated planes and cramp sections, will become evident. 
Further, increased knowledge of the machined surface characteristics and how to alter and improve the properties, such as residual stresses or deformation of the microstructure, would be of great importance. Then, alterations could be tailored to optimise the final surface characteristics. For example, if the final surface is a functional surface, it might require compressive stresses and optimal topography while a surface for joining by welding requires a stress free state in order to prevent distortion.

The main objective of this investigation has been to clarify and gain knowledge of how the surface integrity has been altered by the three high energy methods. The goal is to get a decision basis for selection of the most promising alternative that generates the same characteristics as a conventional fine milling operation. A more detailed description of the objectives will follow in the end of this introduction chapter.

\subsection{Evaluated high energy processes}

The three evaluated high energy methods have the main advantage of being insensitive to the specific material properties of superalloys' such as high strength at elevated temperatures and work hardening, which are the main problems during traditional milling. However, these methods have different impacts upon the attained surface integrity of the machined surface.

Abrasive water jet machining (AWJM) is considered as a potential alternative for this application since it is free from thermal distortion. This method further offers a versatility of materials to be cut, thickness to be cut and generates a surface with high surface finish. AWJM utilise a high pressurised water jet beam that carries the abrasive medium. This abrasive water jet beam strikes the work piece surface and erodes material in the cut. The main influencing process parameters involve abrasive particle size, supply pressure, standoff distance, mass flow rate and cutting speed [2-4]. The later could effectively be used to alter the depth of cut and the surface quality of the machined material. However, it is often reported that the waterjet traverse speed has the most significant influence of the surface finish.

The geometrical aspects of the AWJM cut are of great importance too since the water jet beam greatly influence the geometry of the kerf. This was investigated by Uthayakuma et al. who showed that the wall inclination could be controlled by the traverse speed and water jet pressure when machining Inconel 600 [5]. It was further shown that the material removal rate mainly was controlled by the water jet pressure and abrasive particle velocity. Further, interesting observations were made by Ay et al., who concluded that the surface roughness and angle of the kerf increased with increasing traverse speed while the kerf width decreased [6].

Also, for more complex geometries, abrasive water jet milling is an alternative; however, this requires good control of the depth of cut (DOC). The DOC could be controlled by selecting optimised process parameters that are tailored to the thickness of the material to be cut. This was investigated by Escobar-Palafox for the purpose of pocket milling of Inconel 718 [7]. They showed that the water jet pressure had the greatest influence on both DOC and kerf geometry. However, the water jet pressure has a non-linear behaviour which makes it difficult to predict and adjust. It was further observed that nozzle diameter, abrasive mass flow and feed rate influenced the DOC. A similar investigation was carried out by Goutham et al. for pocket milling of Inconel 825 [8]. The study explored a machining strategy to machine $10 \times 20$ $\mathrm{mm}$ pockets where it was shown that a spiral machining strategy resulted in the highest 3D geometry quality. Further, the overlapping ratio and traverse speed had the greatest influence on the machined geometry. Other investigations of 3D AWJM machining show similar limitations that only rather simple geometries of milled pockets could be achieved $[9,10]$. Machining of more complex 3D geometries is still not solved which implies that this type of operation is still rather difficult and further development is required.

Electrical discharge machining, EDM, is also a possible method to be used, and similarly to AWJM, it is independent of the material to be machined. This method utilises the heat generated by the discharge from two electrodes to erode the work piece material, which is one of the electrodes. The primary erosion mechanism is provided by the discrete discharges between the electrode and work piece. This process transforms the kinetic energies of the electrons into heat and pressure in the cutting zone of the work piece [11]. The local melting is then followed by a subsequent rapid solidification during which a recast layer is formed on the surface. Typical cooling rates involved are in the interval $10^{4}-10^{5}{ }^{\circ} \mathrm{C} / \mathrm{s}$ similarly to the white layer formation during hard turning which was measured by Hosseini et al. for a AISI 52100 steel [12]. This surface layer is commonly referred to as a recast layer (RCL) which has further been described by Kumar et al. and Kruth et al. who divided this into four different sub layers [13, 14]. These are a top layer that is typically hard and brittle with unwanted properties and heat-affected layers. The underlying layers have not been subjected to melting; only heating has a gradual decay with increasing distance which has a softening effect of the material.

The surface integrity after EDM was studied by Newton et al. who investigated the influence of the wire-EDM parameters when machining Inconel 718 [15]. The results showed that a recast layer (RCL) of 5-9 $\mu \mathrm{m}$ was generated regardless of the settings, and further, it was observed that the surface roughness mainly was affected by the energy per spark. Similar results were observed by Li et al. who also found that the RCL had a much lower micro hardness compared to the bulk from the thermal degradation independently of discharge energy [16]. 
In order to minimise the detrimental effect of EDM, so called trim cuts is an alternative machining approach. This was further explored by $\mathrm{Li}$ et al. and Aspinwall et al. [17, 18]. The results showed that a thinner and continuous RCL could be generated, instead of a less controllable and discontinuous RCL, using EDM trim cuts. Such approach also showed that the RCL could be controlled where the rough cut created a $10-\mu \mathrm{m}$ recast layer, but only a few microns for the last two trim cuts. The thermal impact from EDM generates a tensile residual stress in the surface which affects the fatigue life. This was investigated by Jeelani et al. who performed wire-EDM on 3.175-mm-thick Inconel 718 specimens using cutting speeds from 0.5 to $2 \mathrm{~mm} / \mathrm{min}$ [19]. The fatigue life for these samples showed a slight reduction for the EDM samples compared to the virgin material. However, more importantly, the results showed that the fatigue life was not affected by the cutting speed which is surprising since it could be expected that the cutting speed will influence both the extension of RCL as well as the residual stresses.

From an industrialisation perspective, especially for the aero engine industry, the EDM process is already used to some extent. For future production, EDM offers the possibility to machine different combinations of materials as well as machining of large and complex geometries with aid of die sink electrodes. Li et al. compared the material removal efficiency for wire-EDM and die sink-EDM of Inconel 718 [20]. The results showed that the material removal efficiency, MRE, could be considerably improved by utilising a $\mathrm{Cu}-\mathrm{SiC}$ electrode compared to traditional $\mathrm{Cu}$-electrode. An EDM milling setup using several $\mathrm{SiC}$ ceramic electrodes fixated in a spindle that rotates at $3000 \mathrm{rpm}$ was further investigated by Ji et al. $[21,22]$. It was shown that this type of setup would mill a 90$\mathrm{mm}$ circular area with a material removal rate (MRR) of approximately $100 \mathrm{~mm}^{3} / \mathrm{min}$. This is a rather low MRR compared to traditional EDM. In order to improve the MRR further, an alternative EDM method such as additive mixed EDM (AEDM) could be considered. AEDM is a hybrid process that utilises an additive powder in the dielectrics that reduce the insulating strength of the dielectric fluid. This promotes a more stable machining and offers higher MRR and surface quality, further described in references [23, 24]. AEDM was further explored by Wang et al. who showed that MRR of $15,000 \mathrm{~mm}^{3} / \mathrm{min}$ could be reached depending on the discharge current [25]. Further investigations on improving the MRR were presented by Salonitis et al. who performed thermal modelling of the EDM die sink process in order to increase MRR with kept or better surface roughness [26]. That model predicted higher removal rates from an increase of discharge current, the arc voltage or the spark duration which also was verified by experiments.

Laser beam machining, LBM, is the third method that has been considered in this work especially as alternative method for features such as flanks or holes. This method's main advantage is the cutting speed. Traditional $\mathrm{CO}_{2}$ laser has generally a large negative impact on the work piece surface integrity. It has, however, been showed that $\mathrm{ND}: \mathrm{Y}_{3} \mathrm{Al}_{5} \mathrm{O}_{12}$ Garnet (Nd:YAG) laser has less detrimental impact on surface integrity than the $\mathrm{CO}_{2}$ laser [27]. Today, the pulsed Nd:YAG laser is the most employed laser type for LBM, and its impact is much less since it uses a shorter wavelength, $1.064 \mu \mathrm{m}$, compared to $\mathrm{CO}_{2}$, of approximately $10 \mu \mathrm{m}$. This feature becomes advantageous since it reflects less laser light and consequently results in higher absorption which enables machining of highly reflective materials with less laser power [28].

Among other results, the surface integrity after Nd:YAG machining of straight cuts has been reported in several publication $[29,30]$. However, for more complex geometries, Ahmed et al. showed the influence of processing parameters for manufacturing of micro channels in Inconel 718 [31]. The results indicated the presence of recast layer close to the machined surface and longitudinally stretched grains in direction with machining. Hardness testing further showed that the heat-affected zone extended to an area $150 \mu \mathrm{m}$ close to the machined channels.

In order to minimise the effects from the LBM operation, it is of great importance to find the optimal process settings. This was investigated by Ahn et al. who studied the influence of laser power and cutting speed for Nd:YAG laser cutting of Inconel 718 sheet of 1-2 mm thickness [29]. It was shown that the roughness was mainly affected by cutting speed.

The thermal impact from the LBM in Inconel 718 is often mentioned as this method's main disadvantage. The thermal influence was investigated by Ahn et al. who showed that kerf width and the slope of the cut section ranged in the interval $0.53-0.61 \mathrm{~mm}$, respectively, $80.4^{\circ}-86.6^{\circ}$ [32]. In order to decrease the thermal impact from LBM, new techniques utilising dielectric water are developed, also known as wet LBM. An interesting study on this topic was presented by Darwish et al. for processing of micro channels in Inconel 718. That investigation compared dry and wet LBM with Nd:YAG laser [33]. This was realised by either letting the beam pass in air or in dielectric water. The results showed that the wet mode allowed for improved control of the holes to diminish presence of burrs and recast layers. It was further shown that a comparatively low cutting speed, $300-400 \mathrm{~mm} / \mathrm{s}$, was required in order to allow good dimensional stability of the process.

In the literature, as described above, there are separate investigations considering how the performance from different high energy methods is affected by processing parameters. However, there is a large knowledge gap regarding comparisons between different alternatives for machining of complex geometries. The present work aims to gain knowledge on how the three high energy and non-conventional machining methods AWJM, LBM, and EDM affect the generated surface integrity in order to understand how to alter the surface to an acceptable level. These methods will be evaluated as 
alternatives to a conventional milling operation which commonly is used in today's manufacturing. The requirements to meet are set by a typical finish milling operation which often is performed with a ball nose end mill.

Further, each of these high energy methods have different possibilities regarding dimensions that can be processed, cutting speeds, geometrical tolerances, and surface integrity that can be obtained. The main objective of the present work has been to compare and address all of these aspects. This study also aims to highlight what types of measures that needs to be handled by a post process in order to fulfil the requirements for a final surface.

After this introduction section, a detailed description of the material and methods used in this study will follow. In Sect. 3, the results are presented. Section 4 is dedicated to a thorough analysis of the results, and in Sect. 5, a discussion of the results is presented. Finally, in Sect. 6, the main conclusions from these investigations are presented.

\section{Material and methods}

In the present investigation, four different machining alternatives have been compared in order to characterise the surface integrity aspects after machining. The material selection was done from an industrial point of view regarding relevant materials for the application of aero space engine components intended for the hot section of the engine.

\subsection{Material-Alloy 718}

All tests were performed on 8-mm wrought sheet of Alloy 718 in as received condition with the chemical content presented in Table 1. This material was selected in order to allow for a valid comparison of the different non-conventional machining methods. The sheet was machined where the $8 \mathrm{~mm}$ thickness was cut through using EDM, AWJM, and LBM. End milling using a ball nosed end mill with an engagement angle of $15^{\circ}$ was selected as a reference.

\subsection{Material removal methods}

\subsubsection{Laser beam machining}

The laser cutting experiments were performed with a Bystronic Fibre 3015 machine equipped with a fibre optic laser. The cutting operation was performed using best practice parameters as seen in Table 2. The best practice parameters were determined from a screening test using settings based on prior experience from the operator. The experiments were carried with machining speeds of $900-1250 \mathrm{~mm} / \mathrm{min}$ and focus positions of $4-8 \mathrm{~mm}$. The test sample was the same $8-\mathrm{mm}$ wrought material that the final samples were made from. The final surface was inspected visually and parameter selection was done based on roughness appearance and straightness of the waviness of the cut surface.

\subsubsection{Abrasive water jet machining}

The water jet cutting was performed with a Finecut FAW400 abrasive water jet machine. This machine is designed to create a small abrasive beam, down to $0.4 \mathrm{~mm}$. A hard rock garnet abrasive from Barton, with major constituents of $\mathrm{Fe}_{3} \mathrm{Al}_{2}\left(\mathrm{SiO}_{4}\right)_{3}$ and $\mathrm{Mg}_{3} \mathrm{Al}_{2}\left(\mathrm{SiO}_{4}\right)_{3}$, was used as abrasive medium. The cutting was performed with best practice setting according to Table 3 . These parameters were derived from prior knowledge and based on a limited design of experiments where the feed rate and radius compensation were evaluated. Cutting speeds in the interval 9$11 \mathrm{~mm} / \mathrm{min}$ and the radius compensations in the interval 0.2 $0.26 \mathrm{~mm}$ were evaluated. The evaluation was done based on surface roughness and straightness of the cut. The surface roughness was low for all selected cutting speeds and radius compensations which indicated less influence of these parameters in the investigated intervals. Hence, the highest cutting speed of $11 \mathrm{~mm} / \mathrm{min}$ was selected. The cut geometry showed high influence by the radius compensation where $0.2 \mathrm{~mm}$ produced the straightest cut.

\subsubsection{Electrical discharge machining}

The EDM was performed with a Sodick AQ400L machine using a $0.25-\mathrm{mm}$ Bedra megacut wire of $0.25 \mathrm{~mm}$. The machining parameters were selected based on the existing industrial settings used in the production according to Table 4, referred to as best practice for a first rough cut. The priority of the best practice setting for this machining was cutting speed.

\subsubsection{End milling}

Ball nosed end milling was selected as the reference operation since this kind of milling is often used to create final surfaces, especially for complex geometries. The selected machining

Table 1 Chemical specification of the investigated Alloy 718 samples

\begin{tabular}{|c|c|c|c|c|c|c|c|c|c|c|c|c|c|c|c|}
\hline $\begin{array}{l}\mathrm{Ni} \\
{[\%]}\end{array}$ & $\begin{array}{l}\mathrm{Cr} \\
{[\%]}\end{array}$ & $\begin{array}{l}\mathrm{Fe} \\
{[\%]}\end{array}$ & $\begin{array}{l}\mathrm{Nb} \\
{[\%]}\end{array}$ & $\begin{array}{l}\text { Mo } \\
{[\%]}\end{array}$ & $\begin{array}{l}\mathrm{Ti} \\
{[\%]}\end{array}$ & $\begin{array}{l}\mathrm{Al} \\
{[\%]}\end{array}$ & $\begin{array}{l}\mathrm{Co} \\
{[\%]}\end{array}$ & $\begin{array}{l}\mathrm{C} \\
{[\%]}\end{array}$ & $\begin{array}{l}\mathrm{Mn} \\
{[\%]}\end{array}$ & $\begin{array}{l}\mathrm{S} \\
{[\%]}\end{array}$ & $\begin{array}{l}\mathrm{P} \\
{[\%]}\end{array}$ & $\begin{array}{l}\mathrm{Si} \\
{[\%]}\end{array}$ & $\begin{array}{l}\mathrm{W} \\
{[\%]}\end{array}$ & $\begin{array}{l}\mathrm{Cu} \\
{[\%]}\end{array}$ & $\begin{array}{l}\mathrm{B} \\
{[\%]}\end{array}$ \\
\hline 53.9 & 18.5 & 17.8 & 5.02 & 2.87 & 0.98 & 0.47 & 0.16 & 0.039 & 0.08 & $<0.001$ & 0.011 & 0.08 & 0.03 & 0.06 & 0.034 \\
\hline
\end{tabular}


Table 2 Laser machining parameters

\begin{tabular}{lll}
\hline Parameter & Settings & Unit \\
\hline Machine & ByStronic BySprint Fibre 3015 & \\
Laser source & Fibre diod laser & \\
Laser wavelength & $976 \pm 1$ & $\mathrm{~nm}$ \\
Laser power/source & 500 & $\mathrm{~W}$ \\
Number of laser sources & 6 & \\
Total laser power & 3000 & $\mathrm{~W}$ \\
Laser beam diameter & 0.1 & $\mathrm{~mm}$ \\
Cutting speed & 1200 & $\mathrm{~mm} / \mathrm{min}$ \\
Nozzle distance & 0.4 & $\mathrm{~mm}$ \\
Focus position & 6 & $\mathrm{~mm}$ \\
Gas & Nitrogen & \\
Gas pressure & 1.6 & $\mathrm{MPa}$ \\
\hline
\end{tabular}

parameters were based on the recommended settings from the tool manufacturer and were performed using a new tool with the settings presented in Table 5.

\subsection{Examination methods}

\subsubsection{Residual stress}

Residual stress measurements were preformed with X-ray diffraction (XRD) and hole drilling. Both methods are well-established methods to measure residual stresses where X-ray diffraction is more applicable for measuring the surface stresses while hole drilling instead measures deeper residual stresses.

The XRD measurements were performed with a laboratory X-ray diffraction (lab-XRD) equipment from Stresstech, XStress 3000 G2R. This diffractometer was equipped with a Manganese X-ray tube $(\lambda: 0.21031 \mathrm{~nm})$. The lattice plane (311) was measured which has a $2 \theta$ diffraction peak located at $151.88^{\circ}$. The modified $\sin ^{2} \psi$ measurement strategy was used with 5 psi angles $\left(40^{\circ} \ldots-40^{\circ}\right)$. Due to a non linear behaviour of the $d$ versus $\sin ^{2} \psi$, a rotation oscillation of $\pm 10^{\circ}$ was

Table 3 Abrasive water jet cutting parameters

\begin{tabular}{lll}
\hline Parameter & Setting & Unit \\
\hline Machine & Finecut FAW400 & \\
Traverse feed rate & 11 & $\mathrm{~mm} / \mathrm{min}$ \\
Radius compensation & 0.2 & $\mathrm{~mm}$ \\
Pressure & 380 & $\mathrm{MPa}$ \\
Abrasive & Barton Garnet 120 & \\
Nozzle diameter & 0.4 & $\mathrm{~mm}$ \\
Flow & 120 & $\mathrm{~g} / \mathrm{min}$ \\
\hline
\end{tabular}

Table 4 EDM cutting parameters

\begin{tabular}{llc}
\hline Parameter & Setting & Unit \\
\hline Machine & Sodick AQ400L & \\
Machine operation & Wire-EDM & \\
Machining strategy & Roughing & $\mathrm{mm} / \mathrm{min}$ \\
Cutting speed & 7.85 & $\mathrm{~mm}$ \\
Wire diameter & 0.25 & \\
Wire brand & Bedra megacut@plus & \\
Wire composition & CuZn36, gamma messing coating \\
Nozzle gap & 0.158 & $\mathrm{~mm}$ \\
Dielectric fluid & Deionised water & \\
\hline
\end{tabular}

adopted. The residual stress was calculated assuming elastic strain theory according to Hook's law using $199.9 \mathrm{GPa}$ as Young's modulus and 0.29 as Poisson's ratio, further described by Noyan and Cohen [34]. Measurements of residual stress profiles were performed with layer removal where successive material removal was performed by electro polishing. The electro polishing was done with the equipment Struers Movipol and Struers electrolyte A2. All measurements were performed in an accredited laboratory in accordance with the SS-EN 15304:2008 standard that describes how residual stress measurements are performed with X-ray diffraction [35].

The residual stresses determined by means of hole-drilling were performed with a RS-200 equipment and strain gauge from Vishay. This was done using a 1.6-mm diameter drill and a $120 \Omega$ rosette strain gauge (CEA-06-062UL-120). The drilling was performed in the centre of the strain gauge down to a depth equivalent to the radius of the drill. The evaluation was done using the software $\mathrm{H}$-drill where the integral method was adopted for calculation of the stress. Further, the stresses were calculated using Hook's law with a Young's modulus of 199.9 GPa and 0.29 as Poisson's ratio. The evaluation was based on the first $0.8 \mathrm{~mm}$ as the resolution decreases significantly when the depth exceeds $0.8 \mathrm{~mm}$. The measurements

Table 5 Milling parameters

\begin{tabular}{lll}
\hline Parameter & Setting & Unit \\
\hline Machine & DMG 160 & \\
Cutting speed & 30 & $\mathrm{~m} / \mathrm{min}$ \\
Tool type & Ball nosed end mill & \\
Tool ID & Walter H 801111 & \\
Tool diameter & 6 & $\mathrm{~mm}$ \\
Engagement angle & 15 & $\circ$ \\
No. of teeth & 4 & \\
Feed per tooth & 0.08 & $\mathrm{~mm} / \mathrm{tooth}$ \\
Width of cut & 0.4 & $\mathrm{~mm}$ \\
\hline
\end{tabular}


were performed according to the ASTM standard (ASTM E 837-01) in which the procedure is described in detail [36].

\subsubsection{Surface roughness}

The topography was measured using Coherence Scanning Interferometry with a Sensofar $\mathrm{S}$ neox instrument. The roughness measurements were performed over a $878 \times 659-\mu \mathrm{m}$ surface in the centre of the sample at three different positions with a lateral resolution of $0.25 \mu \mathrm{m}$. The measured data was filtered using a spatial median denoise filter with window size of $5 \times 5$ points to reduce short wavelength noise and a robust Gaussian filter with a nesting index of $250 \mu \mathrm{m}$ to remove longer wavelengths. The average value of three measurements for selected parameters from ISO 25178-2:2012 was selected to represent the surface topography [37].

\subsubsection{Microscopy}

The microstructures were evaluated on polished and etched cross sections of the machined surface using optical microscopy and scanning electron microscopy (SEM). The samples for light optical microscopy (LOM) inspection were etched using Kallings solution. The SEM evaluation was done using a Jeol 7800 SEM equipped with a Brucker XFlash 5010 Energy Dispersive Spectroscopy (EDS) detector and a Bruker Electron Back Scatter Diffraction (EBSD) detector.

\section{Results}

The general appearance of the machined surfaces is presented in Fig. 1. These images show a typical appearance from the different machining methods with a repeatable pattern from milling with tracks across the sample in the machining (horisontal). The EDM surface appears to be smooth with a blue coloured tone close to the inlet side of the cut. AWJM surface is also quite smooth but a texture could be observed consisting of grooves across the surface in direction of the water jet beam. Laser machining shows a rather rough and wavy surface texture. This texture differs between the inlet, middle and exit section relative to the laser beam entrance, which is the top in the image. The inlet shows lower waviness compared to the middle section and the exit. The darker region below the entrance is located at the laser focus position.

\subsection{Topography}

The different surfaces show entirely different topographical characteristics both in terms of surface roughness as well as texture, seen in the 3D illustrations of Fig. 2.

The milled surface has a texture from the milled tracks with a specific repeated pattern in direction along and across the feed. The LBM and AWJM surfaces show instead only one directional feature in the texture, directed along with the cut. The EDM surface shows an isotropic surface texture. Regarding surface roughness, LBM results in the roughest surface followed by EDM. Both the AWJM and the milled surface show relatively high surface finish with a low surface roughness as seen in Table 6 . The arithmetic mean height, $\mathrm{Sa}$, shows that this surface has low roughness which is also observed in the ten point height parameter (S10z). This indicates lowest global average peak height for the milled surface. The skewness (Ssk) differentiates the two surfaces more indicating that the
Fig. 1 General appearance of the machined surfaces
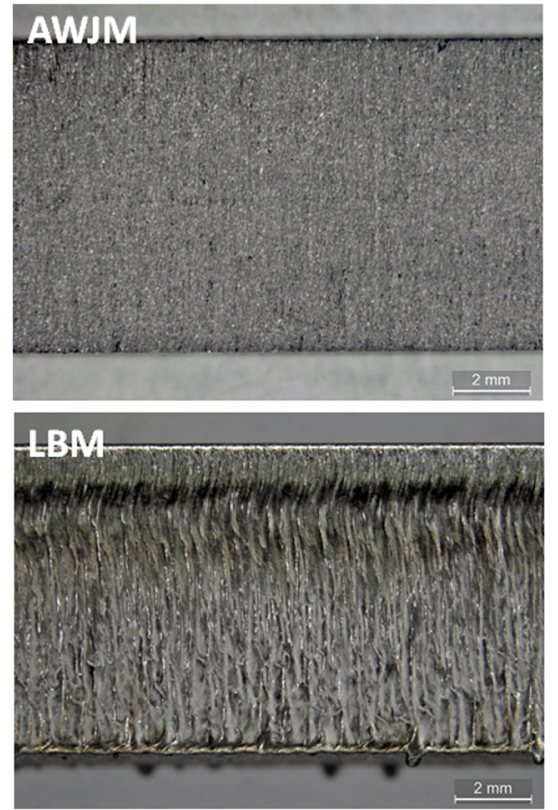
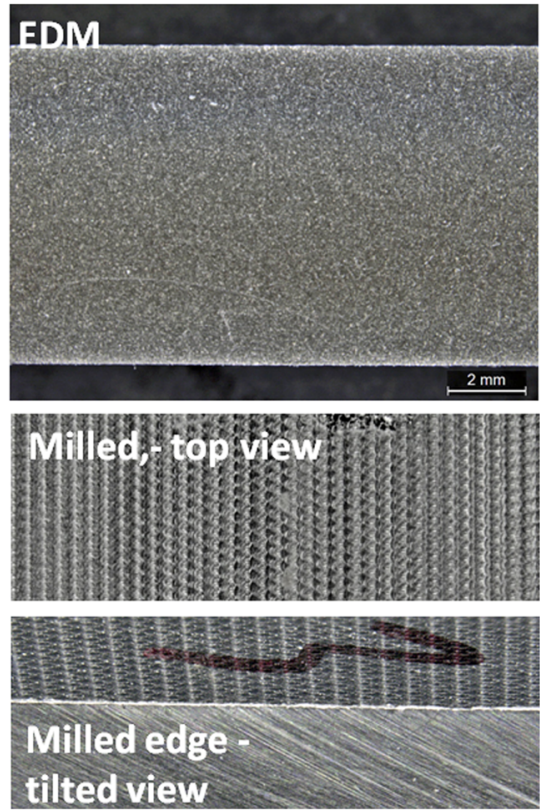

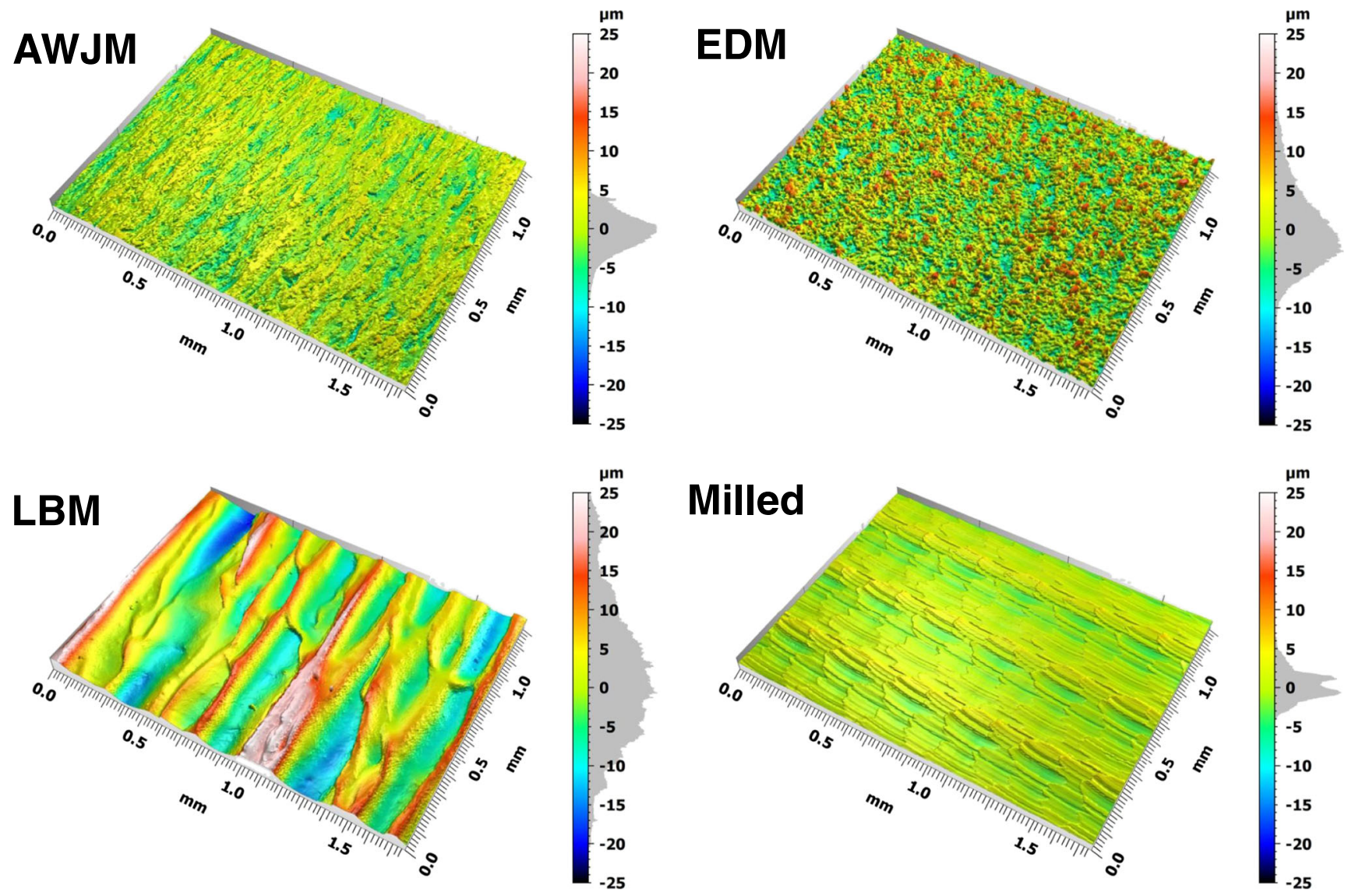

Fig. 2 3D views of the different surfaces where the scale bars show histograms of the height distributions for the different surfaces

milled surface contains lots of peaks on a plane while AWJ is composed of one plateau with fine valleys.

Further investigations of the surface chemistry were performed for the AWJM surface using SEM. The results clearly show traces from the abrasive medium both in terms of scratches across the surface and embedded abrasive particles in the surface, shown in Fig. 3. This figure illustrates the surface appearance at the outlet position relative the abrasive water jet beam entrance. At this location, several small particles could be observed where one large is marked with the yellow arrow in the figure. These particles were further identified using chemical EDS mapping analysis. EDS identified the elements silicon $(\mathrm{Si})$, aluminium $(\mathrm{Al})$ and oxygen $(\mathrm{O})$ which are constituents of the abrasive medium.

\subsection{Geometry of the cut}

The geometry of the cut was measured on polished cross sections for the different samples as presented in Fig. 4. The geometry of the cut was measured at the inlet and outlet position of the sample where the inlet refers to the laser beam entrance, the AWJM beam entrance and the top side of the EDM cut of the sample. The outlet refers, respectively, to the exit of the laser beam, AWJM beam and the bottom side of the EDM cut. The summarised results are presented in Table 7 which shows that the EDM generates an almost straight cut comparable to the milled surface. Both LBM and AWJM show rather high deviations at the inlet and outlet positions of the cut.

Table 6 Selected ISO25178-2 parameters for the different surfaces [37]

\begin{tabular}{|c|c|c|c|c|c|c|c|c|c|c|c|c|c|c|}
\hline Sample & $\mathrm{Sq}[\mu \mathrm{m}]$ & st.dev & Ssk & st.dev & Sku & st.dev & $\mathrm{Sp}[\mu \mathrm{m}]$ & st.dev & $\mathrm{Sv}[\mu \mathrm{m}]$ & st.dev & $\mathrm{Sa}[\mu \mathrm{m}]$ & st.dev & $\mathrm{S} 10 \mathrm{z}[\mu \mathrm{m}]$ & st.dev \\
\hline Milled & 1.7 & 0.04 & 0.3 & 0.04 & 2.9 & 0.04 & 6.2 & 0.24 & 4.2 & 0.05 & 1.3 & 0.03 & 7.9 & 0.62 \\
\hline EDM & 4.6 & 0.07 & 0.7 & 0.03 & 3.3 & 0.07 & 22.4 & 3.63 & 13.4 & 1.61 & 3.7 & 0.06 & 22.7 & 1.95 \\
\hline AWJM & 2.3 & 0.04 & -0.4 & 0.10 & 3.4 & 0.39 & 7.8 & 0.83 & 10.8 & 2.34 & 1.8 & 0.02 & 13.0 & 1.31 \\
\hline LBM & 7.5 & 0.82 & -0.04 & 0.42 & 2.8 & 0.32 & 25.3 & 1.63 & 19.1 & 1.80 & 6.1 & 0.54 & 31.0 & 3.72 \\
\hline
\end{tabular}


Fig. 3 EDS mapping of the AWJM outlet positions where a large oxide particle was identified, marked with a yellow arrow
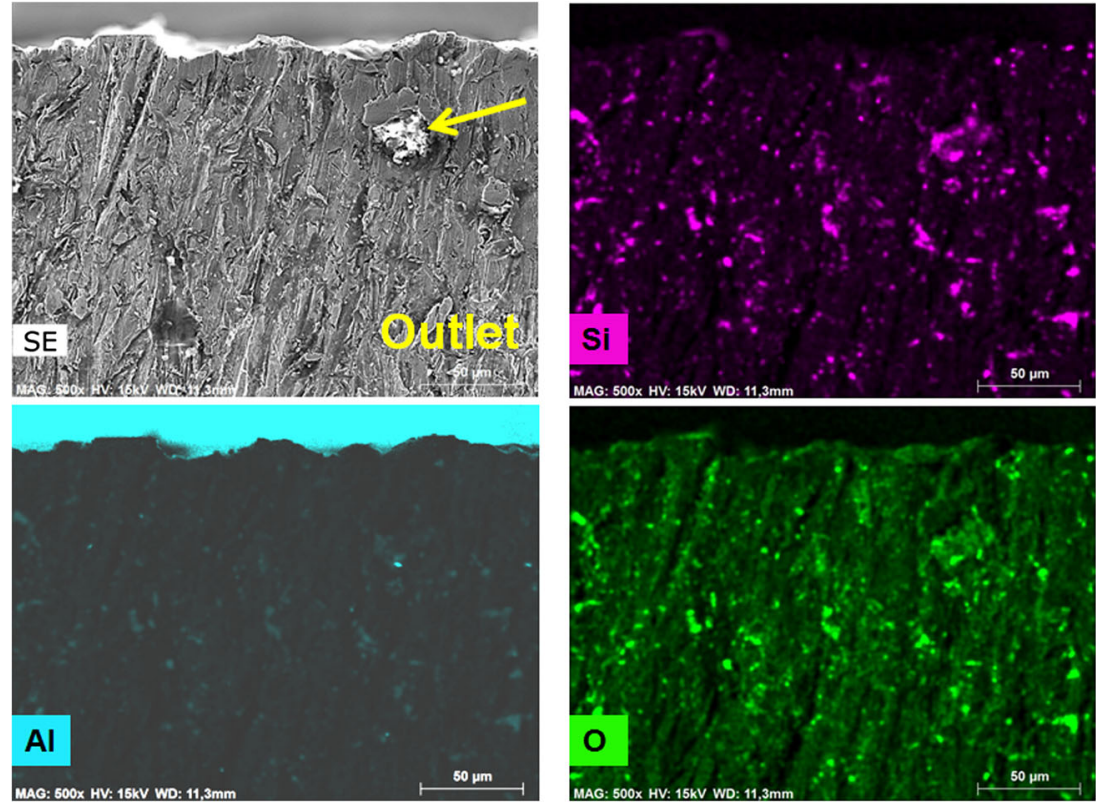

\subsection{Residual stresses}

The as received residual stress state of the wrought Alloy 718 sheet was measured using hole drilling in the centre of a cold mounted and polished cross section of the sheet. The result showed an averaged residual stress state in the bulk of $18 \mathrm{MPa}$ with a standard deviation of $\pm 33 \mathrm{MPa}$ over a depth interval of $0.5 \mathrm{~mm}$ below the surface. These results have been plotted as dotted reference lines in Fig. 5.

The residual stress profile measurements show a great influence of the different machining methods according to Fig. 5. For the milled surface, a low tensile stress is measured in the surface interval of $0-6 \mu \mathrm{m}$ which gradually changes into a rather high compressive residual stress with a maximal compressive residual stress of -

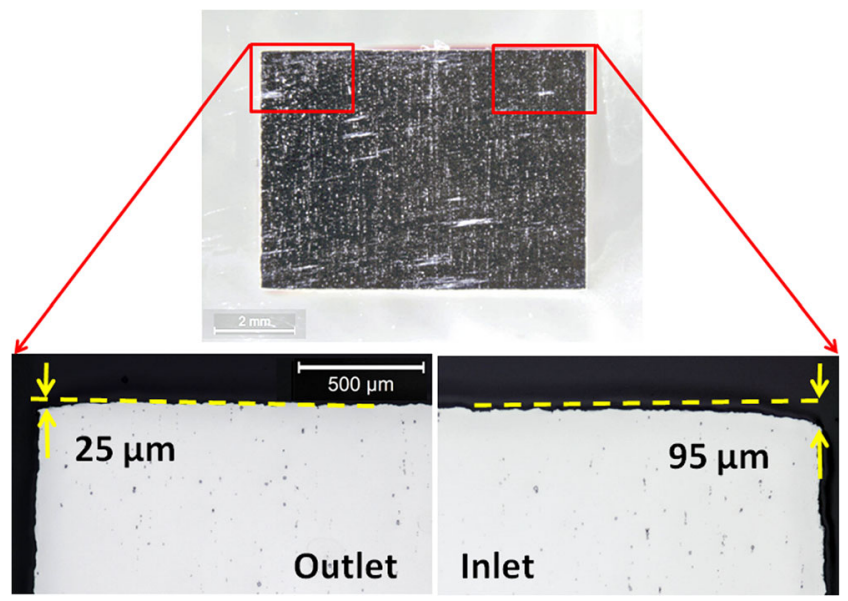

Fig. 4 Light optical micrographs of the cross section of the abrasive water jet cut surface for inlet and outlet positions in $\times 200$ magnification
$700 \mathrm{MPa}$ at a depth of $70 \mu \mathrm{m}$. Measurements down to a depth of $500 \mu \mathrm{m}$ show a compressive stress state of $116 \mathrm{MPa}$ which indicate a great impact from the milling operation.

The AWJM surface is in compressive residual stress state to a depth of $50 \mu \mathrm{m}$ while for greater depths, the stress levels out towards a stress free state at a depth of $200 \mu \mathrm{m}$.

Finally, LBM and EDM show instead tensile residual stresses. The heat impact from both of these methods differs, and hence, the surface states and the penetration depths differ between these two samples. Similar to AWJM, the EDM sample shows only an impact to a depth of $50 \mu \mathrm{m}$, and for greater depths, the state is close to stress free. There is, however, a difference where the very outer surface has a $318 \mathrm{MPa}$ lower residual stress compared to the measurement $5 \mu \mathrm{m}$ below the surface which instead is $514 \mathrm{MPa}$. The laser machined sample has a much deeper impact, and even at depth below $300 \mu \mathrm{m}$, the residual stresses are above $200 \mathrm{MPa}$.

Further investigation of the depth impact of the laser machined sample was performed using hole drilling. Figure 6

Table 7 Summary of the deviation measurement for the ideal straight cut

\begin{tabular}{lll}
\hline Sample & $\begin{array}{l}\text { Inlet deviation } \\
{[\mu \mathrm{m}]}\end{array}$ & $\begin{array}{l}\text { Outlet deviation } \\
{[\mu \mathrm{m}]}\end{array}$ \\
\hline AWJM & 95 & 25 \\
Laser & 150 & 110 \\
EDM & $<1$ & $<1$ \\
Milled & 0 & 0 \\
\hline
\end{tabular}


Fig. 5 Residual stress profiles for the evaluated machining methods in feed direction (along the sample surface)

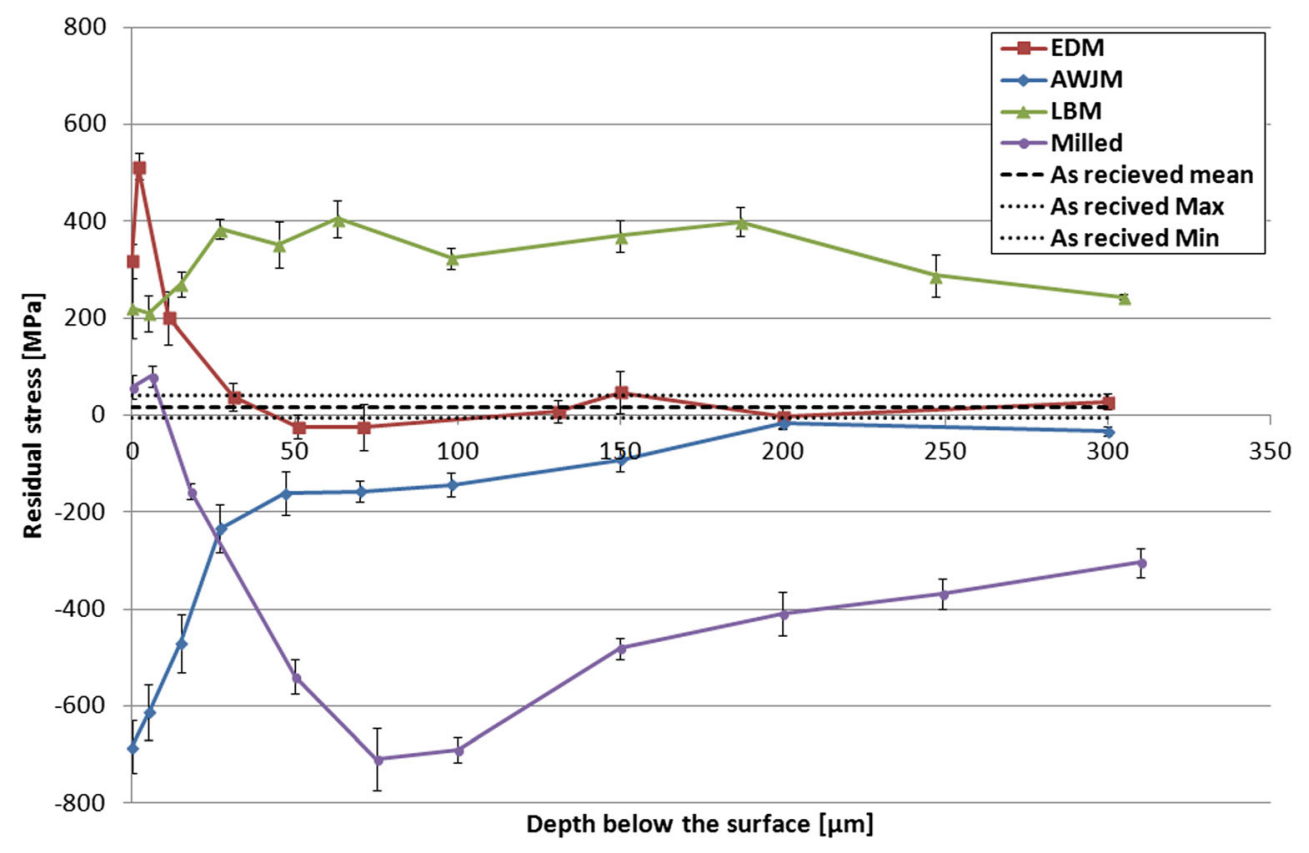

illustrates both the lab-XRD measurements and the hole drilling which shows that the stress level is tensile even at a depth of $1 \mathrm{~mm}$. The results also indicate a difference between the lab-XRD and hole drilling results which show that the labXRD measures lower tensile stresses in the surface region.

The full width half maximum (FWHM) profiles are calculated data from the diffraction peaks. This is frequently used as a measurement of the work hardening from different processing. The results indicate a shallow impact for the alternative techniques but rather deep for milling, as seen in Fig. 7. Milling also shows the highest FWHM surface value.
Further, AWJM shows the highest surface value of the alternative techniques but shallowest impact compared to milling.

\subsection{Microstructure}

The microstructure was evaluated using LOM on polished and etched cross sections of the machined surfaces according to Fig. 8. The results show distinct differences between the different machining methods and how the microstructure at the surface has been altered.
Fig. 6 Residual stress profiles for the laser beam machined surface measured using lab-XRD and hole drilling

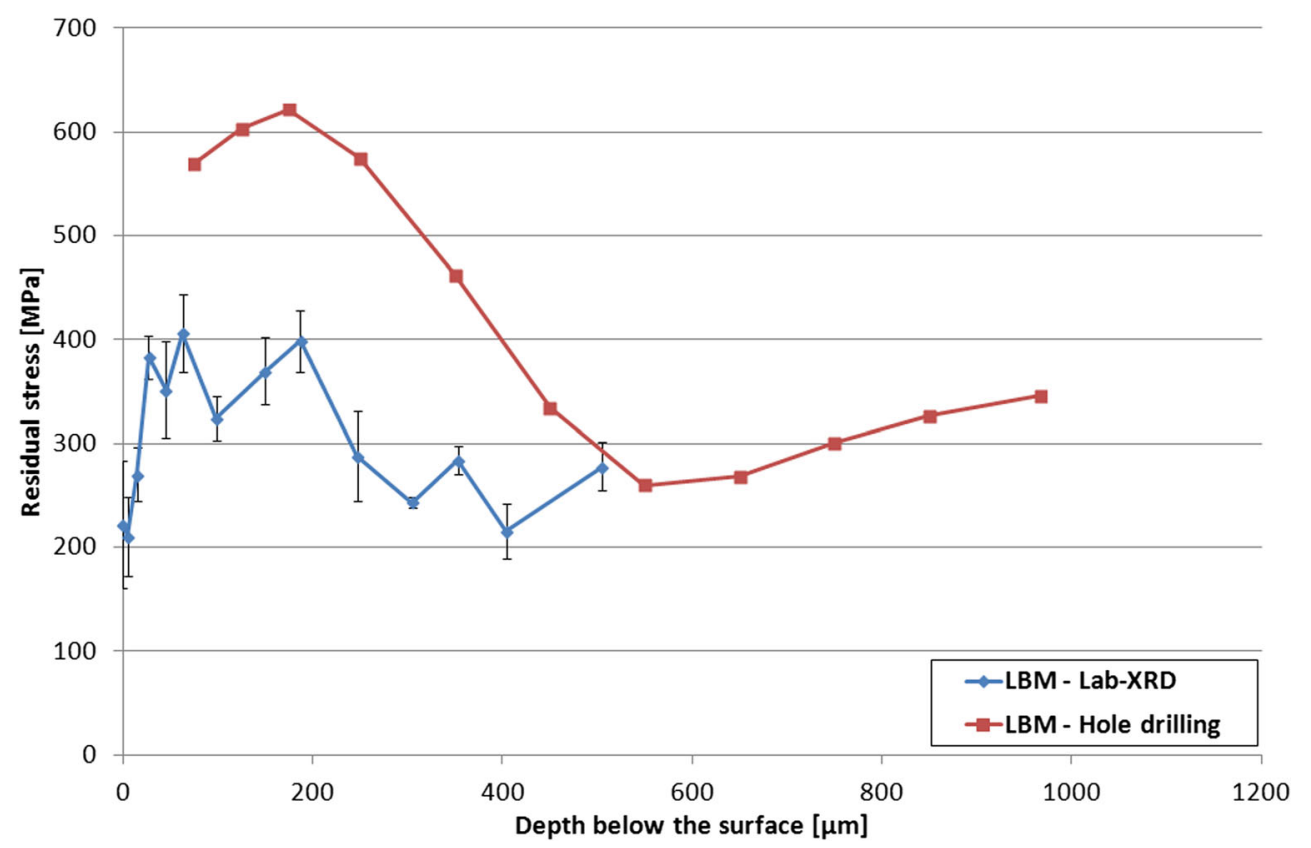


Fig. 7 Full Width Half Maximum (FWHM) profiles for the evaluated machining methods in feed direction (along the sample surface)

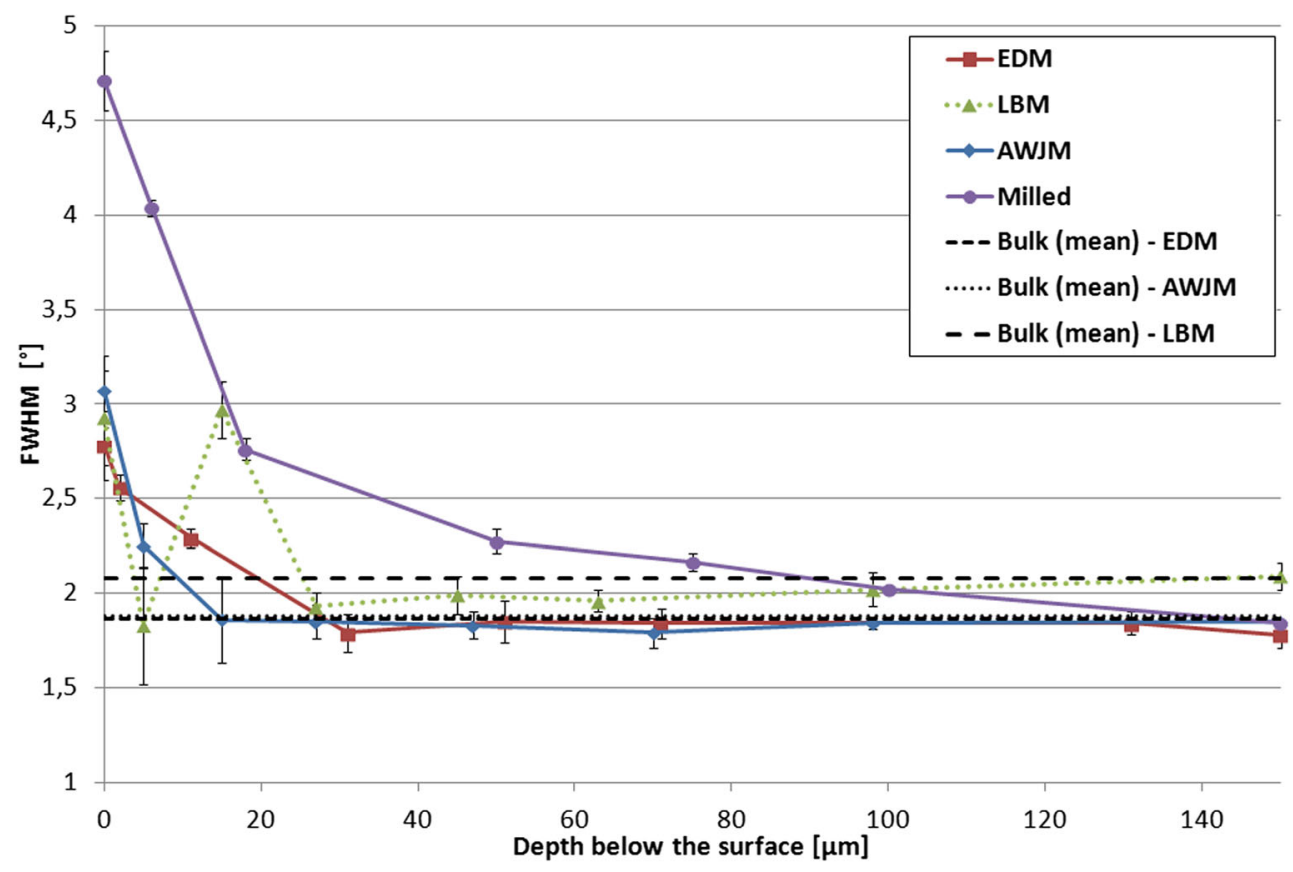

The milled surface has a smooth topography but is highly deformed shown by stretched grain boundaries. The deformation is localised to a top layer of $10 \mu \mathrm{m}$.

The AWJM surface shows no alterations in the surface but instead a rather uneven topography where the grains at the surface have been cut right trough by the water jet beam.

The EDM surface shows a discontinuous layer of recast layer appearing as a bright layer. The grains in the surface are refined due to the heat impact to a depth of few micrometres.
The LBM surface shows a rather thick continuous, 30$50 \mu \mathrm{m}$, remelted layer on the surface. Underneath the remelted layer, the grains appear to have abnormal size due to grain growth which extends below $1 \mathrm{~mm}$ from the surface.

Further investigations of the surface microstructure were analysed using high-resolution FEG-SEM and EBSD. Figure 9 illustrates the surfaces from the SEM back scatter detector for the different machining methods in $\times 2000$ magnification. In this magnification, the actual affected surface
Fig. 8 Light optical micrographs of the microstructure after machining from light optical microscopy in $\times 1250$ magnification
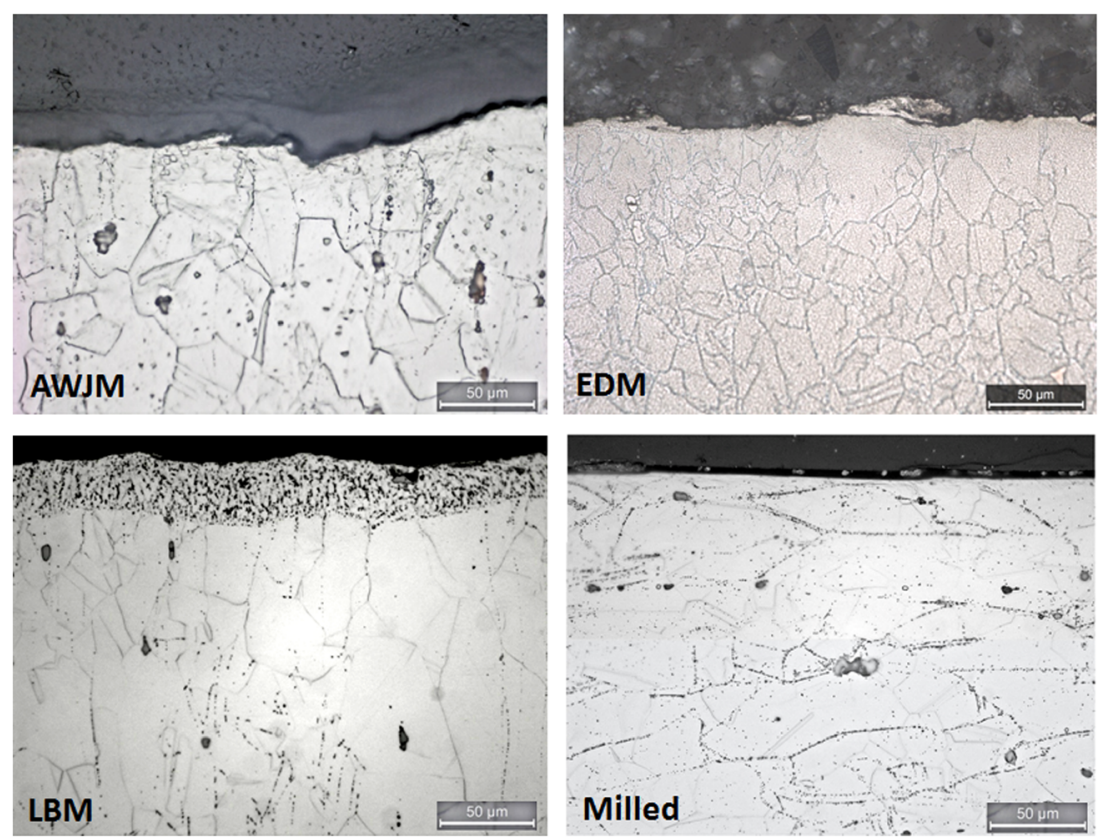
Fig. 9 Micrographs of the microstructure after machining from SEM back scatter detector in $\times 2000$ magnification
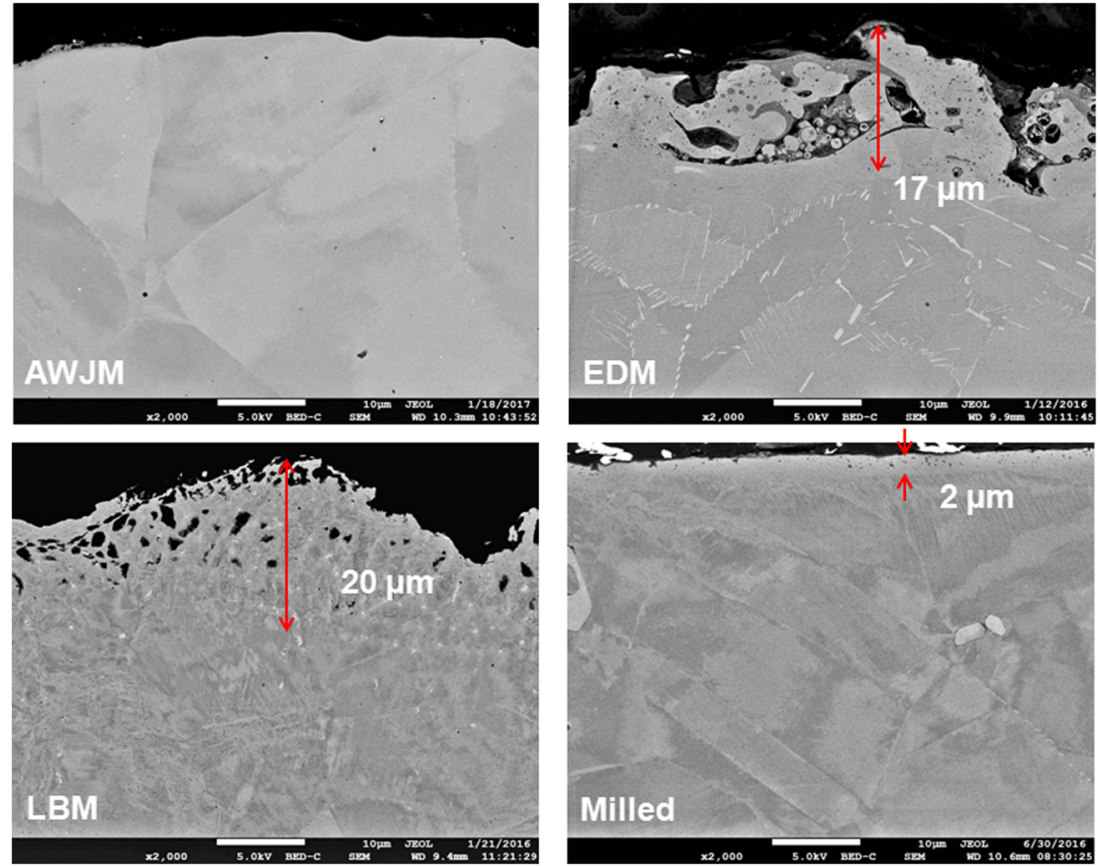

zone could be measured. For EDM, the recast layer has an extension of 10-20 $\mu \mathrm{m}$. For LBM, the re-melted surface has a porous structure and an extension in the interval 10-30 $\mu \mathrm{m}$. The outer layer of a few micrometres for the milled surface is highly deformed while the AWJM surface does not show any impact at all.

The impact on the grains from the machining is shown in Fig. 10. This figure illustrates the grain maps for the different samples from EBSD analysis. The different colours represent different grains.

For both AWJM and the milled sample, only a very shallow impact could be observed down to a few micrometres under the surface. A white reference line was added to the images illustrating the outer surface. It could further be seen that the AWJM, milling and especially the LBM have a black surface layer which indicate low or no diffraction data from this
Fig. 10 EBSD grain maps in $x$ 800 magnification showing the different grains in different colours from the different machining operations
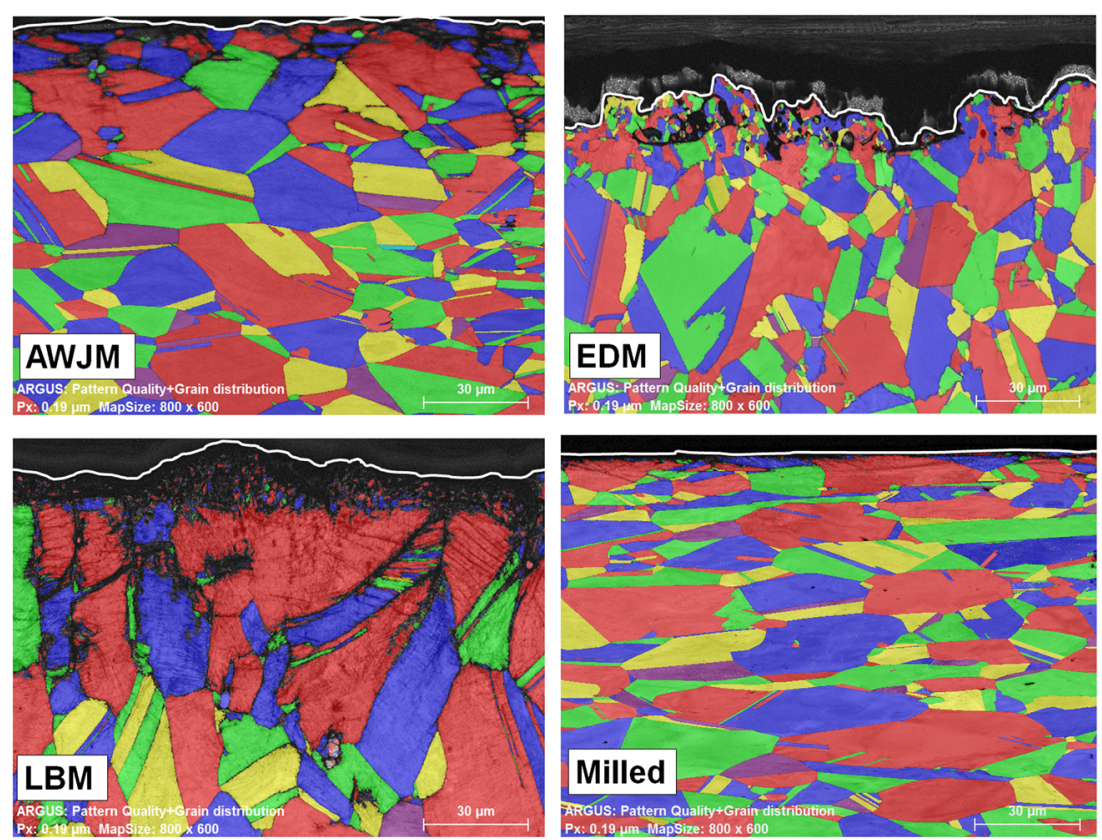
region. This will subsequently result in non indexed phase when measuring with EBSD.

The EDM surface shows a splattered recast layer with a rather discontinuous and uneven surface topography. LBM show grain refinement and non index material of the outer most $10-15 \mu \mathrm{m}$. Below this depth, the grain growth is abnormal with grain sizes of $50-80 \mu \mathrm{m}$.

In Fig. 11, the misorientation maps from the EBSD measurements are presented. The misorientation illustrates how much individual grains are reoriented relative one and other which also is an indication of the built up strains between and within the grains. The blue coloured areas show low degree of misorientation while the red areas show high degree of misorientation.

The milled surface shows an impact in the surface region of $10 \mu \mathrm{m}$. It could further be observed a thin layer of a few micrometres with non index material.

The grains in the surface region for the AWJM surface show individual grains with rather high misorientation, typically to a depth of 30-40 $\mu \mathrm{m}$.

The EDM surface shows lowest degree of impact while the LBM shows the highest degree of impact extended far into the surface. Even at depths of several hundreds of microns, the misorientation is comparably high.

\section{Analysis of results}

The key performance indicators (KPI) used for evaluation of surface integrity aspects after machining in these investigations were selected based on literature surveys. For example, the review performed by Jawahir et al. gives an insightful overview of how different surface integrity aspects could be investigated [38]. The investigated machining methods are known to generate different surface alterations which can be characterised by topography, residual stresses and alterations of the near surface microstructure. Relevant properties are therefore surface roughness, surface residual stresses, maximum residual stress and microstructural depth impact. The analysis of the results of these KPIs for the different machining methods will be described in detail in this section and summarised at the end for comparison.

\subsection{Machining performance}

The investigated machining methods offer great difference both regarding processing time as well as how the surface integrity has been affected. The results in this investigation clearly show that the different methods influence the surface integrity differently and may be suitable for different applications and work piece thicknesses.

Generally, laser beam machining offers the highest cutting speed, which in this investigation during initial screening tests reached up to $1290 \mathrm{~mm} / \mathrm{min}$. The results showed that LBM is not suitable for a thicker sheet since the impact is detrimental both in terms of microstructure, topography and residual stresses.

According to literature, the work piece thickness limit for AWJM is almost unlimited but in reality, and in the case for steel, published results show thicknesses up to $100 \mathrm{~mm}[39$,
Fig. 11 EBSD misorientation maps in $\times 800$ magnification illustrates built up strains between individual grains in the microstructure from the different machining operations
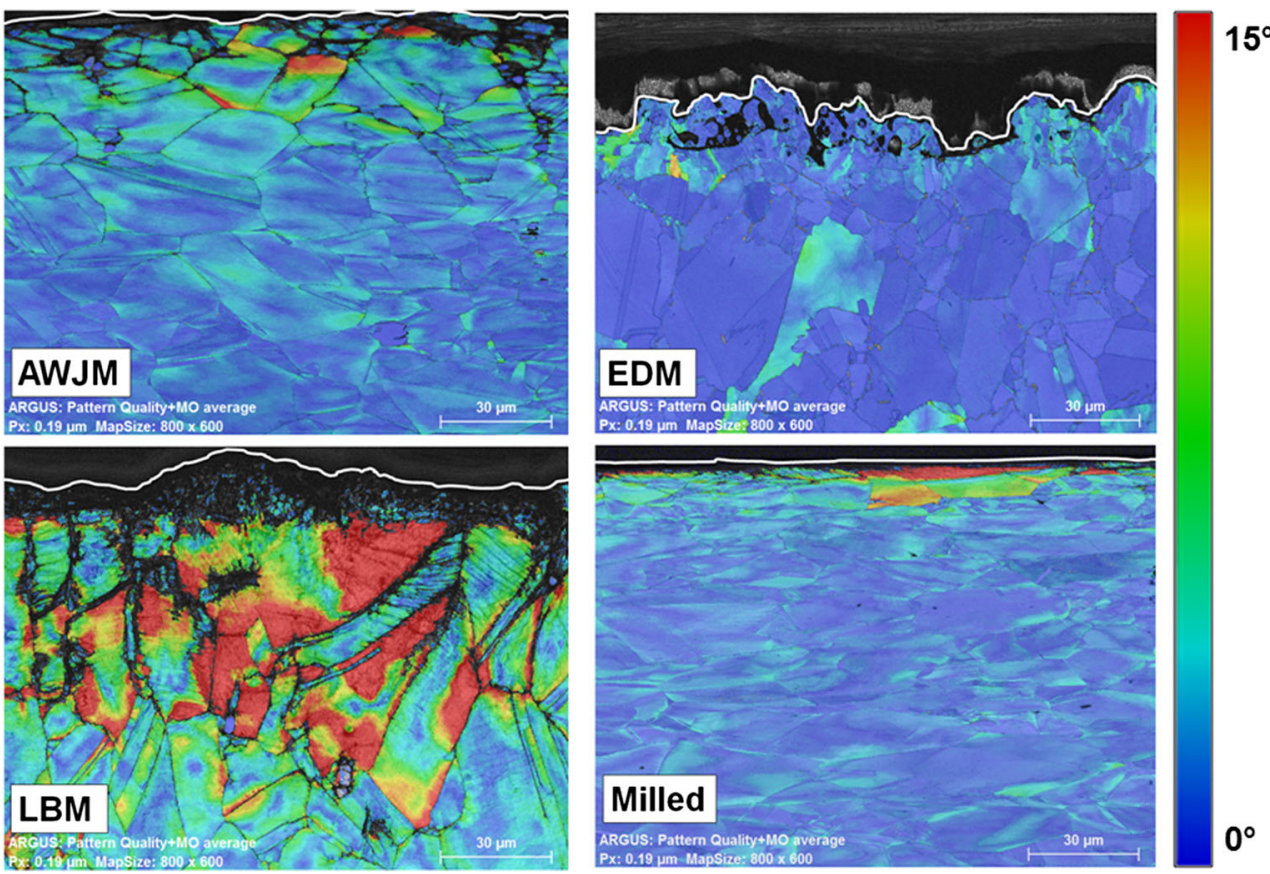
40]. The machining thickness for Alloy 718 is in the interval 0 $30 \mathrm{~mm}$, e.g. Fenoughty et al. who reported of work piece thicknesses of $25.4 \mathrm{~mm}$ machined at a cutting speed of $50.8 \mathrm{~mm} / \mathrm{min}$ [30]. However, there is a trade off between thickness, cutting speed and the surface finish for AWJM that need to be kept in mind. For the 8-mm-thick work piece in this investigation, the resulting surface finish had high quality when a cutting speed of $11 \mathrm{~mm} / \mathrm{min}$ was used which is slower relative to LBM.

EDM had similar cutting speed as AWJM but generated a coarser surface. The thickness limitation is even more generous for EDM than for AWJM. The exact limit is defined by the machine geometry and wire diameter but machining is typically performed in the thickness interval $0-500 \mathrm{~mm}$. Related work was performed by the authors in ref. [41] where a cast billet with a thickness of $600 \mathrm{~mm}$ of Inconel 718 was EDM:ed into a shaft with a thickness of $100 \mathrm{~mm}$.

\subsection{Geometry of the cut}

Both milling and EDM show an almost straight cut when observing the edge of the machined surface. However, for both AWJM and LBM, the deviation from a straight cut was obvious since it deviates with $25-150 \mu \mathrm{m}$. Investigation of the cross section for the AWJM cut shows that the geometrical imperfection differs between the inlet, $25 \mu \mathrm{m}$, and outlet position, $95 \mu \mathrm{m}$. This deviation is due to the kerf created by the erosion mechanism when machining which has strongest affect at the outlet side. This machining was performed by an abrasive water jet machine, Finecut FAW400, which is designed to create a small AWJM beam which also seems to have an improved influence on the kerf.. The results presented by Uthayakumar showed a ten times higher kerf taper compared to the one machined in this investigation [5].

For LBM, the geometrical deviation and appearance also differed between the inlet and outlet, $110-150 \mu \mathrm{m}$, which is due to the material evaporation and the external gas pressure used to remove material in the cut zone. The geometrical taper for the LBM cut is in similar magnitude as reported by Darwish et al. [33] who showed how the taper was influenced by different laser powers.

\subsection{Surface integrity}

\subsubsection{Topography}

The milled surface showed the highest quality of all machining methods regarding topography closely followed by AWJM. EDM and especially LBM showed instead a relatively high surface roughness. Worth noticing is that milling, AWJM and LBM create specific textures on the cut surface where the two later generates texture across the surface. EDM on the other hand produced an isotropic surface texture with similar roughness as presented by Aspinwall et al. [18].

The AWJM surface showed abrasive residue observed as embedded large and finer particles in the surface. Similar problems were reported by Ay et al. [6] and a method to handle this was proposed by Huang et al. who used the AWJM method both to machine and clean the surface of Ti-6Al-4V [42].

\subsubsection{Residual stresses}

AWJM produced the most preferable residual stress state with fairly high compressive residual stresses in the surface region. The milled surface resulted in a shallow tensile stress in the surface that rapidly changes into a rather deep compressive residual stress profile. This profile is much higher and deeper compared to the AWJM sample, which is only affected to a depth of $200 \mu \mathrm{m}$ depth. Even at depths of $0.5 \mathrm{~mm}$, a compressive stress of - $160 \mathrm{MPa}$ was measured indicating deep impact from the machining operation.

The residual stresses from EDM are tensile with a depth impact of $40 \mu \mathrm{m}$. This is similar to results presented by Newton et al. who showed tensile residual stresses at the surface and down to $10-15 \mu \mathrm{m}$ [15]. The difference in penetration depth is most likely due to the fact that parameters for a rough cut were employed in this investigation. To address this tensile residual stress state, a post process such as shot peening could be used. Further, a $200 \mathrm{MPa}$ lower stress was measured in the surface compared to $5 \mu \mathrm{m}$ below the surface. This difference is most likely due to the fact that the surface measurement is made in the recast layer which has a lower stress state than the heat-affected material.

The detrimental effect of LBM is clearly visible in the residual stress profile showing a rather high tensile stress that increase below the surface. Hole drilling was applied in order to study how deep the influence was and the results showed tensile stresses even at a depth of $0.8 \mathrm{~mm}$ below the surface. This result was correlated to the measured profile from the labXRD which showed a difference of 100-200 MPa. The measured difference is most likely due to the fact that the two methods measure different types of stresses where hole drilling is more sensitive for macro stresses while lab-XRD is more sensitive for micro stresses.

\subsubsection{Microstructure}

The alteration and deformation of the surface microstructure differed a lot between the different machining concepts. The AWJM surface showed the least impact for all four methods in terms of deformation and generation of surface alterations based on the investigations of FWHM and optical microscopy. 
The black layer in the misorientation maps from the EBSD data for the AWJM, milled and LBM samples are the result of lack of indexing from these areas. This could either be due to grain refinement if the grains are too small, typically less than approximately $20 \mathrm{~nm}$, from plastic deformation. This is most likely the case for the thin black layer observed for the milled and AWJM samples. The lack of indexing for LBM is more likely due to the result of the thermal impact in combination with reaction to the atmosphere that creates new phases that are not indexed as nickel.

However, the misorientation map for the AWJM sample showed higher values $30-40 \mu \mathrm{m}$ below the surface as well as overall increased misorientation values throughout the complete map image. This is probably the result of the deformation from the abrasive bombardment that has deformed the surface layer.

Milling resulted in a high degree of mechanical deformation which was observed in the FWHM measurements. These measurements further indicated an impact to a depth of 100-150 $\mu \mathrm{m}$. The misorientation maps showed similar results where the very outer layer of $10 \mu \mathrm{m}$ is plastically deformed. Below this depth, the misorientation values are comparably high in the complete depth of the image map. It was further observed a thin white etching layer at the very outer surface. This layer indicates a highly deformed surface which further is indicated by the lack of indexing of the diffraction data.

The microstructure of the EDM surface shows a discontinuous recast layer consisting of remelted material and oxides appearing as a porous structure with an extension in the interval 5-15 $\mu \mathrm{m}$. This recast layer needs to be removed by a post processing operation since it has different and unknown material properties compared to the core. The EBSD data further revealed a grain refinement at the outer surface but almost no impact in the misorientation maps.

The microstructure of the LBM sample also shows remelted material but to a greater extent, approximately $20 \mu \mathrm{m}$. The re-melted layer showed a porous structure that most likely is the results from the built up heat and pressure that interact with the material during the cutting. However, this remelted material appears to be more continuous compared to the RCL from EDM. Further, it could be observed in the EBSD data that the impact from LBM has generated rather high strains in the microstructure and to depths of several hundreds of micrometres. In contrast to the EDM microstructure, the LBM has generated grain growth to abnormal size with grains larger than $100 \mu \mathrm{m}$.

\subsubsection{Summary of analysis}

Table 8 summarises these results which show that EDM and AWJM are both possible alternatives to conventional milling that would greatly lower the processing time. However, due to the EDM method's ability to machine complex geometries as well as that EDM is used to some extent in today's aero engine manufacturing, this method is a stronger alternative.

\section{Discussion}

The present investigation intends to compare the performance of different machining methods in order to meet the requirements of today's standard which is a fine milled surface. The machining methods used in this study have been shown to generate similar surface characteristics as reported in the literature for the specific types of machining operations. However, it may be debated how general these results are, and the reality is that these results are general in that under these certain machining conditions and the specific machines used. This investigation show distinct differences from the different machining comparable to other available results reported in the literature. These results could therefore be considered as important guidance when selecting new alternative manufacturing routes to meet the future design strategies of topological designed parts.

The summarised outcome shows that AWJM is the most promising alternative in respect to surface integrity based on topography, residual stresses and impact on the microstructure. However, the main issues to consider for AWJM relate to residue of the abrasive media which has been shown to have a negative impact on the fatigue strength [42]. EDM is also a promising alternative resulting in a geometrical perfect cut with a rather shallow impact but the recast layer and tensile stresses require post processing.

Table 8 Summary of the different KPI used for surface integrity evaluations

\begin{tabular}{|c|c|c|c|c|c|c|c|}
\hline Machining method & Topography & Texture & $\begin{array}{l}\text { Cut geometry } \\
\text { Kerf }\end{array}$ & $\begin{array}{l}\text { Surface residual } \\
\text { stress }\end{array}$ & $\begin{array}{l}\text { Residual } \\
\text { stress profile }\end{array}$ & $\begin{array}{l}\text { Microstructure, } \\
\text { surface alteration }\end{array}$ & $\begin{array}{l}\text { Surface } \\
\text { deformation }\end{array}$ \\
\hline Milling & ++ & - & + & - & ++ & - & - \\
\hline EDM & - & + & + & - & - & - & + \\
\hline AWJM & + & - & - & ++ & + & - & - \\
\hline LBM & - & - & - & - & - & - & - \\
\hline
\end{tabular}


Regarding the residual stress state, it is not obvious what kind of stress state that is desirable for the application at hand. Generally, a compressive residual stress state is most often required from a fatigue perspective. For thinner materials such as slender components or sheet metals, the desirable stress state instead depends upon what the surface will be used for. For example, for a sheet surface that is to be welded in order to join an additively manufactured feature, the residual stress state should be as close to zero as possible in order to prevent distortion. However, if a finish machined surface will be used in operation, a compressive residual stress state is preferable from a fatigue strength perspective. Based on that reasoning, a tensile residual stress is not preferable and needs to be addressed. Post processing using shot peening is frequently employed to tackle this and generates quite high compressive residual stresses. These results show the importance of knowing what kind of stress state that is present in the material in order to optimise the stress profile for the application at hand.

Results from the lab-XRD data regarding FWHM show an interesting correlation to the amount of deformation for the different machined surfaces. This measurement gives the possibility to parameterise the amount of deformation which showed that the milling resulted in the highest deformation compared to EDM and AWJM. This parameter was further able to differentiate the remelted layer of the LBM.

The results clearly show that LBM is not suitable for this application due to the high heat impact from the laser in relation to the thickness of the work piece. The high cutting speed involved for LBM is the main motive for using this method but this comes at the expense of generating really deep and detrimental surface integrity characteristics. However, for thinner sheets, LBM could still be an alternative but then thorough surface integrity investigations are required to determine impact and appropriate post processing.

End milling was used as a reference for this type of application. However, the surface integrity is greatly influenced by milling method and parameters used. For example, the engagement angle influences the acting forces which were investigated further by Aspinwall et al. [18]. That investigation clearly showed that the approach angle greatly influenced both the residual stresses, topography and the deformation. Among others, one important difference from the non-conventional machining methods is that milling generates a plastically deformed layer. This is not the case for the EDM and AWJM where instead the surfaces show no or very low amount of deformation of the surface.

When selecting between the two main candidates as alternatives to milling, EDM and AWJM, both are considered as highly attractive. Both methods allow to drastically increasing the material removal rates; however, it is obvious that both methods require similar type of post processing. From a surface integrity perspective, AWJM has an advantage, but from an industrialisation perspective, the
EDM method would, however, be preferred. This is mainly due to this method's ability to machine complex geometries, utilising for example a die tool, and that it is already used to some extent in today's aero engine manufacturing.

\section{Conclusions}

The results from this investigation, where four different machining techniques have been used with specific machining parameters, lead to the following conclusions.

Milling with a ball nosed end mill using a $15^{\circ}$ engagement angle generates a surface with low surface roughness, a shallow tensile surface residual stress that becomes compressive below the surface and a plastically deformed surface layer.

Abrasive water jet machining generates a highly desirable surface with a slightly rougher surface than the milled surface, a compressive residual stress state and no alteration of the surface microstructure but with embedment of abrasive particles in the surface. This makes AWJM the best alternative to milling of the evaluated machining methods in this investigation.

EDM generates a surface with isotropic texture and coarser surface roughness compared to the AWJM surface, a tensile residual stress state in the surface region and a surface containing a discontinuous recast layer.

Both AWJM and EDM are possible alternatives for machining of 8-mm-thick Alloy 718 but both methods require post processing to handle undesirable effects from the machining.

Laser beam machining is not a suitable machining method for the application of machining 8- mm-thick Alloy 718 sheets due to its negative impact resulting in high tensile residual stresses, high surface roughness and deep alterations of the microstructure for the machined work piece.

Acknowledgments Special thanks to GKN Aerospace Sweden AB for supplying test materials, information and expertise in the involved processes. The author would also like to acknowledge Swerea IVF, the KKfoundation and the SiCoMap research school for all support.

Funding information The majority of the results in this thesis work have been part of the research projects G5Demo-2 (Ref. no. 2013-04666) and SweDemo (Ref. no. 2015-06047) funded by VINNOVA, the Swedish Government agency within the Ministry of Enterprise.

Open Access This article is distributed under the terms of the Creative Commons Attribution 4.0 International License (http:// creativecommons.org/licenses/by/4.0/), which permits unrestricted use, distribution, and reproduction in any medium, provided you give appropriate credit to the original author(s) and the source, provide a link to the Creative Commons license, and indicate if changes were made.

Publisher's Note Springer Nature remains neutral with regard to jurisdictional claims in published maps and institutional affiliations. 


\section{References}

1. Ezugwu EO, Wang ZM, Machado AR (1999) The machinability of nickel-based alloys: a review. J Mater Process Technol 86:1-16. https://doi.org/10.1016/S0924-0136(98)00314-8

2. Bendsøe MP, Kikuchi N (1988) Generating optimal topologies in structural design using a homogenization method. Comput Methods Appl Mech Eng 71:197-224. https://doi.org/10.1016/ 0045-7825(88)90086-2

3. Sigmund O, Maute K (2013) Topology optimization approaches. Struct Multidiscip Optim 48:1031-1055. https://doi.org/10.1007/ s00158-013-0978-6

4. Schaub A, Ahuja B, Butzhammer L, Osterziel J, Schmidt M, Merklein M (2016) Additive manufacturing of functional elements on sheet metal. Phys Procedia 83:797-807. https://doi.org/10.1016/ j.phpro.2016.08.082

5. Uthayakumar M, Khan MA, Kumaran ST, Slota A, Zajac J (2016) Machinability of nickel-based Superalloy by abrasive water jet machining. Mater Manuf Process 31:1733-1739. https://doi.org/10. 1080/10426914.2015.1103859

6. Ay M, Çaydaş U, Hasçalik A (2010) Effect of traverse speed on abrasive waterjet machining of age hardened Inconel 718 nickelbased Superalloy. Mater Manuf Process 25:1160-1165. https://doi. org/10.1080/10426914.2010.502953

7. Escobar-Palafox GA, Gault RS, Ridgway K (2012) Characterisation of abrasive water-jet process for pocket milling in Inconel 718. Procedia CIRP 1:404-408. https://doi.org/10. 1016/j.procir.2012.04.072

8. Goutham U, Hasu BS, Chakraverti G, Kanthababu M (2016) Experimental investigation of pocket milling on Inconel 825 using abrasive water jet machining - Inpressco. Int J Curr Eng Technol 6: 295-302

9. Alberdi A, Rivero A, López de Lacalle LN (2011) Experimental study of the slot overlapping and tool path variation effect in abrasive waterjet milling. J Manuf Sci Eng 133:034502-034504. https://doi.org/10.1115/1.4004320

10. Hashish M (1989) An investigation of milling with abrasivewaterjets. J Eng Ind 111:158-166. https://doi.org/10.1115/1. 3188745

11. Ekmekci B, Tekkaya AE, Erden A (2006) A semi-empirical approach for residual stresses in electric discharge machining (EDM). Int J Mach Tools Manuf 46:858-868. https://doi.org/10. 1016/j.ijmachtools.2005.07.020

12. Hosseini SB, Beno T, Klement U, Kaminski J, Ryttberg K (2014) Cutting temperatures during hard turning - measurements and effects on white layer formation in AISI 52100. J Mater Process Technol 214:1293-1300. https://doi.org/10.1016/j.jmatprotec. 2014.01.016

13. Kruth J-P, Stevens L, Froyen L, Lauwers B (1995) Study of the white layer of a surface machined by die-sinking electro-discharge machining. CIRP Ann Manuf Technol 44:169-172. https://doi.org/ 10.1016/S0007-8506(07)62299-9

14. Kumar S, Singh R, Singh TP, Sethi BL (2009) Surface modification by electrical discharge machining: a review. J Mater Process Technol 209:3675-3687. https://doi.org/10.1016/j.jmatprotec. 2008.09.032

15. Newton TR, Melkote SN, Watkins TR, Trejo RM, Reister L (2009) Investigation of the effect of process parameters on the formation and characteristics of recast layer in wire-EDM of Inconel 718. Mater Sci Eng A 513:208-215. https://doi.org/10.1016/j.msea. 2009.01.061

16. Li L, Wei XT, Li ZY (2014) Surface integrity evolution and machining efficiency analysis of W-EDM of nickel-based alloy. Appl Surf Sci 313:138-143. https://doi.org/10.1016/j.apsusc.2014.05.165
17. Li L, Guo YB, Wei XT, Li W (2013) Surface integrity characteristics in wire-EDM of Inconel 718 at different discharge energy. Procedia CIRP 6:220-225. https://doi.org/10.1016/j.procir.2013. 03.046

18. Aspinwall DK, Soo SL, Berrisford AE, Walder G (2008) Workpiece surface roughness and integrity after WEDM of Ti$6 \mathrm{Al}-4 \mathrm{~V}$ and Inconel 718 using minimum damage generator technology. CIRP Ann Manuf Technol 57:187-190. https://doi.org/10. 1016/j.cirp.2008.03.054

19. Jeelani S, Collins MR (1988) Effect of electric discharge machining on the fatigue life of Inconel 718. Int J Fatigue 10:121-125. https:// doi.org/10.1016/0142-1123(88)90040-0

20. Li L, Li ZY, Wei XT, Cheng X (2015) Machining characteristics of Inconel 718 by sinking-EDM and wire-EDM. Mater Manuf Process 30:968-973. https://doi.org/10.1080/10426914.2014.973579

21. Ji R, Liu Y, Zhang Y, Cai B, Li X (2011) High-speed end electric discharge milling of silicon carbide ceramics. Mater Manuf Process 26:1050-1058. https://doi.org/10.1080/10426914.2010.529590

22. Ji R, Liu Y, Zhang Y, Dong X, Chen Z, Cai B (2011) Experimental research on machining characteristics of $\mathrm{SiC}$ ceramic with end electric discharge milling. J Mech Sci Technol 25:1535-1542. https:// doi.org/10.1007/s12206-011-0327-x

23. Mohd Abbas N, Solomon DG, Fuad Bahari M (2007) A review on current research trends in electrical discharge machining (EDM). Int J Mach Tools Manuf 47:1214-1228. https://doi.org/10.1016/j. ijmachtools.2006.08.026

24. Ho K, Newman S (2003) State of the art electrical discharge machining (EDM). Int J Mach Tools Manuf 43:1287-1300. https://doi. org/10.1016/S0890-6955(03)00162-7

25. Wang F, Liu Y, Shen Y, Ji R, Tang Z, Zhang Y (2013) Machining performance of Inconel 718 using high current density electrical discharge milling. Mater Manuf Process 28:1147-1152. https:// doi.org/10.1080/10426914.2013.822985

26. Salonitis K, Stournaras A, Stavropoulos P, Chryssolouris G (2009) Thermal modeling of the material removal rate and surface roughness for die-sinking EDM. Int J Adv Manuf Technol 40:316-323. https://doi.org/10.1007/s00170-007-1327-y

27. Hasçalık A, Ay M (2013) CO2 laser cut quality of Inconel 718 nickel - based superalloy. Opt Laser Technol 48:554-564. https:// doi.org/10.1016/j.optlastec.2012.11.003

28. Dubey AK, Yadava V (2008) Laser beam machining - a review. Int J Mach Tools Manuf 48:609-628. https://doi.org/10.1016/j. ijmachtools.2007.10.017

29. Ahn D-G, Byun K-W (2009) Influence of cutting parameters on surface characteristics of cut section in cutting of Inconel 718 sheet using CW Nd:YAG laser. Trans Nonferrous Metals Soc China 19: s32-s39. https://doi.org/10.1016/S1003-6326(10)60241-5

30. Fenoughty KA, Jawaid A, Pashby IR (1994) Machining of advanced engineering materials using traditional and laser techniques. J Mater Process Technol 42:391-400. https://doi.org/10.1016/ 0924-0136(94)90145-7

31. Ahmed N, Darwish S, Alahmari AM, Shar MA (2016) Microchannels by Nd:YAG laser beam machining: fabrication, microstructures, and micro-hardness profiles. Int J Adv Manuf Technol 85:1955-1968. https://doi.org/10.1007/s00170-015-7257-1

32. Ahn DG, Byun KW, Kang MC (2010) Thermal characteristics in the cutting of Inconel 718 Superalloy using CW Nd: YAG laser. J Mater Sci Technol 26:362-366. https://doi.org/10.1016/S10050302(10)60059-X

33. Darwish S, Ahmed N, Alahmari AM, Mufti NA (2016) A comparison of laser beam machining of micro-channels under dry and wet mediums. Int J Adv Manuf Technol 83:1539-1555. https://doi.org/ 10.1007/s00170-015-7658-1

34. Noyan IC, Cohen JB (1987) Residual stress measurement by diffraction and interpretation, 1987th edn. Springer-Verlag, New York 
35. European Commitee for Standardization (2008) EN 15305:2008 E, Non-destructive testing - test method for residual stress analysis by $\mathrm{X}$-ray diffraction

36. ASTM International (2013) ASTM E837 - 13a, Standard test method for determining residual stresses by the hole-drilling strain-gage method

37. International Organisation for Standarization (2012) ISO 25178-2: 2012, Geometrical product specifications (GPS) - Surface texture: areal-Part 2: terms, definitions and surface texture parameters

38. Jawahir IS, Brinksmeier E, M'Saoubi R et al (2011) Surface integrity in material removal processes: recent advances. CIRP Ann Manuf Technol 60:603-626. https://doi.org/10.1016/j.cirp.2011.05.002

39. Ohlsson L (1995) The theory and practice of abrasive water jet cutting. Thesis, LTU
40. Folkes J (2009) Waterjet - an innovative tool for manufacturing. J Mater Process Technol 209:6181-6189. https://doi.org/10.1016/j. jmatprotec.2009.05.025

41. Holmberg J, Wretland A, Berglund J (2016) Grit blasting for removal of recast layer from EDM process on Inconel 718 shaft: an evaluation of surface integrity. J Mater Eng Perform 25:5540-5550. https://doi.org/10.1007/s11665-016-2406-8

42. Huang L, Kinnell P, Shipway PH (2013) Parametric effects on grit embedment and surface morphology in an innovative hybrid waterjet cleaning process for alpha case removal from titanium alloys. Procedia CIRP 6:594-599. https://doi.org/10.1016/j.procir. 2013.03.077 